$17^{\circ}$ ERGODESIGN

\& USIHC 2019

PUC-Rio, 11 a 13 de dezembro

Rio de Janeiro, RJ, Brasil $17^{\circ}$ Ergodesign - Congresso Internacional de Ergonomia e Usabilidade de Interfaces Humano Tecnológica: Produto, Informações Ambientes Construídos e Transporte

$17^{\circ}$ USIHC - Congresso Internacional de Ergonomia e Usabilidade

de Interfaces Humano Computador

\title{
Agradabilidade Percebida em Salas de Aula para o Ensino Superior
}

\author{
Perceived Pleasantness in Higher Education Classroom
}

\author{
ACIOLI, Patrícia Barbosa (1); \\ Universidade Federal de Pernambuco, Mestranda em Ergonomia / PPERGO \\ patriciacioli@gmail.com \\ COSTA FILHO, Lourival (2) \\ Universidade Federal de Pernambuco, Doutor em Desenvolvimento Urbano \\ lourivalcosta@yahoo.com
}

\section{RESUMO}

Este artigo objetiva fornecer informações empíricas sobre os efeitos de duas características de salas de aula para ensino superior - complexidade e coerência - na agradabilidade percebida. Como procedimentos metodológicos, uma Sentença Estruturadora, instrumento básico da Teoria das Facetas, foi adotada no desenho da investigação empírica, que optou por um questionário online para coletar os dados e pelos gráficos produzidos através do Formulário Google para interpretá-los. Os principais resultados empíricos obtidos corroboram, apenas parcialmente, com os efeitos da complexidade e da coerência postulados para a agradabilidade percebida para o tipo de ambiente enfocado.

salas de aula para ensino superior, agradabilidade percebida, ergonomia do ambiente construído.

\begin{abstract}
This article aims to provide empirical information on the effects of two characteristics of higher education classrooms - complexity and coherence - on perceived pleasantness. As methodological procedures, a Mapping Sentence, a basic instrument of Facet Theory, was adopted in the design of the empirical investigation, which opted for an online questionnaire to collect the data and graphs produced through the Google Form to interpret them. The main empirical results partially corroborate the effects of complexity and coherence postulated for the perceived pleasantness for the type of environment focused.
\end{abstract}

higher education classrooms, perceived pleasantness, ergonomics of the built environment.

\section{INTRODUÇÃO}

Ao longo dos anos, cada vez mais estudantes têm tido acesso ao ensino superior, o que contribui para o aumento no número de instituições de ensino superior (IES) no país. Muitas 


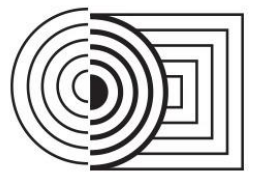

\section{$17^{\circ}$ ERGODESIGN \& USIHC 2019 \\ PUC-Rio, 11 a 13 de dezembro \\ Rio de Janeiro, RJ, Brasil}

$17^{\circ}$ Ergodesign - Congresso Internacional de Ergonomia e Usabilidade

de Interfaces Humano Tecnológica: Produto, Informações Ambientes

Construídos e Transporte

$17^{\circ}$ USIHC - Congresso Internacional de Ergonomia e Usabilidade

de Interfaces Humano Computador

vezes esse aumento na quantidade de oferta por cursos de nível superior nos faz questionar o comprometimento com a qualidade do ensino e do aprendizado, mas também traz à tona indagações quanto à adequabilidade dos ambientes de ensino e aprendizagem nessas IES. Em 1951, Anísio Teixeira já afirmava que nenhum outro elemento é tão fundamental no complexo da situação educacional, depois do professor, quanto o prédio e suas instalações. Podemos trazer essa percepção para a realidade dos ambientes de ensino superior, considerando que a sala de aula tem como finalidade dar suporte ao processo de formação do aluno, sendo de grande importância no processo de construção do aprendizado.

Rapuano Guidalli (2012) expõe que, com a vivência diária é natural que qualquer aluno da graduação ou professor conheça bem o ambiente de sala de aula. No entanto, essa vivência tem sido desconsiderada na sua concepção, haja vista que vários problemas de ordem espacial causam desconforto - aos usuários de salas de aula teórica - em universidades.

Ressaltando a importância do projeto dos ambientes de ensino, pode-se destacar que, para Sanoff (2001), o ambiente de sala de aula contribui para a aprendizagem quando ele é cuidadosamente projetado e busca atender às necessidades individuais, tanto de professores como de alunos.

Entende-se que as decisões projetuais para ambientes de salas de aula têm efeitos sobre as questões do ensino e aprendizagem, considerando que o espaço resultante do projeto será a interface que permitirá as trocas e proporcionará a adequação do ambiente, o que aponta para um enfoque nos domínios da ergonomia do ambiente construído.

De acordo com Villarouco (2011), a ergonomia do ambiente extrapola as questões puramente arquitetônicas, focando seu posicionamento na adaptabilidade e conformidade do espaço às tarefas e atividades que neles serão desenvolvidas, mas também mediados pelo sentimento e percepção do usuário. Dessa forma, os ambientes relacionam-se também com fenômenos de ordem subjetiva, que se identificam com elementos espaciais, podendo interferir no desempenho do usuário na realização de suas tarefas.

Nesse contexto, a investigação empírica desta pesquisa, partindo da formulação de uma sentença estruturadora, instrumento básico da Teoria das Facetas, foi delineada e tomou como categorias (facetas) duas características ambientais de salas de aula para ensino superior, complexidade e coerência, pelas suas possíveis influências na qualidade visual percebida. Apesar de os arquitetos teorizarem sobre a qualidade do ambiente construído, as análises empíricas da agradabilidade percebida em salas de aula, geralmente ficam para trás. Por tudo isso, este artigo objetiva prover informações empíricas sobre os efeitos da complexidade e da coerência em salas de aula, para o ensino superior, na agradabilidade percebida. De modo mais específico, busca examinar a influência dessas duas características na agradabilidade percebida em salas de aula para o ensino superior.

Diversas características dos elementos ambientais podem ter particular relevância para a resposta estética, incluindo, por exemplo, como acima exposto, a complexidade e a coerência. Para sua aplicação na metodologia de projeto, entretanto, é importante determinar se esses atributos são proeminentes na percepção e na avaliação do público.

Apesar de essas respostas avaliativas, por si só, não poderem prever o comportamento real do usuário, a avaliação combinada de respostas avaliativas e do comportamento previsto dá uma boa indicação do comportamento real (NASAR, 1988). Assim, na presente pesquisa, os respondentes foram solicitados a indicar em que medida gostariam de assistir à aula, estar e permanecer em várias salas de aula para ensino superior, com diferentes níveis de complexidade e de coerência, instrução de pesquisa que foi relacionada com a expressão da agradabilidade percebida pelos participantes da pesquisa para esses locais.

Do ponto de vista de sua importância para a metodologia ergonômica do ambientes construído, 


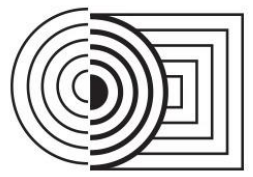

\section{$17^{\circ}$ ERGODESIGN \& USIHC 2019 \\ PUC-Rio, 11 a 13 de dezembro \\ Rio de Janeiro, RJ, Brasil}

$17^{\circ}$ Ergodesign - Congresso Internacional de Ergonomia e Usabilidade de Interfaces Humano Tecnológica: Produto, Informações Ambientes Construídos e Transporte

$17^{\circ}$ USIHC - Congresso Internacional de Ergonomia e Usabilidade

de Interfaces Humano Computador

esta pesquisa se justifica por poder contribuir com informações norteadoras à elaboração de projetos e, por conseguinte, em um sentido mais amplo, favorecer a qualidade visual percebida em salas de aula do ensino superior, às necessidades afetivas de seus usuários, uma vez que, o fazer projetual não pode estar resumido ao ato de projetar um edifício ou ambiente que simplesmente funcione.

Para Rykwert (2004), arquitetos por muito tempo se contentaram em ser vistos como homens de bom gosto, para se transformar - em meados do século XX - em gerentes e especialistas que fazem os edifícios funcionar, e depois acrescentam o componente estético.

Por isso, a abordagem ergonômica desta pesquisa - que se propõe a contribuir com a fase de concepção de projetos - considera necessário o entendimento de que o ambiente construído pode influenciar o comportamento humano, de modo que as pessoas estão mais propensas a frequentar ambientes percebidos favoravelmente e evitar outros que julgem negativos.

\section{CONSIDERAÇÕES TEÓRICAS}

Quando se pensa em salas de aula, a imagem que costuma vir à mente são as tradicionais salas com carteiras enfileiradas de frente para a lousa. Essa imagem não está apenas no repertório de muitos indivíduos que passaram pelas carteiras escolares, mas permanece no imaginário de quem frequentou também o ensino superior.

Nos dias atuais, com o aumento da demanda escolar e também da oferta de cursos em instituições de ensino superior, a arquitetura para esse tipo de instituição tornou-se bastante padronizada, desde os projetos de arquitetura escolar, como é o caso das escolas padrão FNDE, até instituições de ensino superior particulares, onde a padronização também tornou-se uma prática comum, com um partido arquitetônico voltado à racionalidade construtiva, privilegiando a funcionalidade, seguindo critérios puramente econômicos e focados na rapidez de execução, fatores que convergem na presença de muitos prejuízos em seus resultados. Fernández-Ramírez, Rebolloso e Cantón (2007) afirmam, baseados em resultados de pesquisas anteriores, que a qualidade da sala de aula está relacionada à sua legibilidade, à ausência de conflitos sinergéticos (a estimulação excessiva, os ruídos e a falta de privacidade visual ou vistas de janela que tirem a atenção do aluno), e a condições básicas de conforto ambiental.

A ergonomia, como a tecnologia projetual das comunicações entre humanos e máquinas, trabalho e ambiente (MORAES; MONT'ALVÃO, 2000), está interessada em contribuir com pesquisas sobre novas formas de pensar o projeto do ambiente de trabalho que, nesta pesquisa, é o ambiente de sala de aula para ensino superior, esforçando-se para que bons resultados sejam obtidos.

Com esse propósito, é importante criar bases objetivas para decisões de projeto para espaços de salas de aula para ensino superior e, a partir deste ponto, este artigo trará alguns postulados teóricos que embasam a preferência ambiental e sua avaliação, com o propósito principal de apoiar as discussões dos resultados empíricos desta pesquisa.

É importante ressaltar que a sala de aula é um ambiente dinâmico, que precisa de elementos arquitetônicos que capacitem a reestruturação de seu espaço, a fim de alcançar os objetivos propostos. Sua identidade deve refletir a identidade de seus usuários, seus pensamentos, suas memórias e ações. Uma sala sem identidade é inexpressiva, amorfa e traduz um ensino pobre. (RAPUANO GUIDALLI, 2012)

Para prosseguir, é preciso lembrar que Kaplan (1988) define o julgamento ambiental como produto de dois processos relacionados com a sobrevivência humana: "envolvimento" e "fazer 


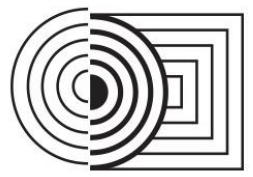

\section{$17^{\circ}$ ERGODESIGN \& USIHC 2019 \\ PUC-Rio, 11 a 13 de dezembro \\ Rio de Janeiro, RJ, Brasil}

$17^{\circ}$ Ergodesign - Congresso Internacional de Ergonomia e Usabilidade

de Interfaces Humano Tecnológica: Produto, Informações Ambientes

Construídos e Transporte

$17^{\circ}$ USIHC - Congresso Internacional de Ergonomia e Usabilidade

de Interfaces Humano Computador

sentido", na medida em que um ambiente deve ser envolvente para atrair a atenção e fazer sentido a fim de que se possa operar nele. A complexidade e a coerência são características ambientais relevantes, respectivamente relacionadas com cada um desses dois processos. A complexidade diz respeito à "diversidade" dos elementos na cena, ou seja, ao número de diferentes elementos visíveis e a distinção entre eles. A literatura destaca que pouca complexidade é monótona; muita é estressante. O nível intermediário é, presumivelmente, mais prazeroso (BERLYNE,1972; WOHLWILL, 1976; NASAR, 2000).

A coerência é definida como o grau em que a cena se encaixa, incluindo fatores que facilitam a organização do plano da imagem, sua compreensão e estruturação, podendo reduzir a incerteza e aumentar o tom hedônico (beleza ou agradabilidade). Auxiliando a compreensão, a coerência (alcançada através da redução do contraste entre os elementos da cena) pode reduzir a incerteza e aumentar o tom hedônico (KAPLAN, 1988).

Diversas características ambientais podem ter particular relevância para a resposta estética, incluindo, por exemplo, complexidade e coerência.

Apesar de a qualidade visual percebida depender, em parte, de fatores perceptuais/cognitivos, ela é, por definição, um julgamento emocional que envolve avaliação e sentimentos (NASAR, 1988). Como resultado, a agradabilidade percebida é medida aqui através de julgamentos avaliativos para cenas de salas de aula, para ensino superior, escolhidas a partir da manipulação sistemática das características de complexidade e coerência, essa última avaliada aqui através de uma covariável, qual seja: contraste.

Sendo assim, o referencial teórico exposto acima e proposto por Kaplan e Kaplan (1982), a partir de Kaplan (1988), tem particular relevância nesta pesquisa, assim como as evidências empíricas de Ward e Russel (1981), conforme apresentado em Russel (1988), que tratam das avaliações afetivas de lugares.

Para serem relevantes, esses julgamentos afetivos devem centrar-se nas dimensões da avaliação que as pessoas realmente usam para avaliar os lugares. Utilizando uma variedade de estratégias de pesquisa, James Ward e Larry Russel encontraram quatro dimensões notáveis para o ambiente: agradável, estimulante, excitante, relaxante. O agradável é uma dimensão puramente avaliativa, enquanto o estímulo independe da dimensão avaliativa. A excitação e o relaxamento envolvem misturas de avaliação e estímulo. Desse modo, as pessoas experienciam lugares emocionantes como mais agradáveis e estimulantes do que chatos; e experienciam lugares relaxantes como mais agradáveis e menos estimulantes do que angustiantes.

Baseando-se nos achados de Ward e Russel, esta pesquisa avaliará a agradabilidade de várias cenas de salas de aula para o ensino superior.

Sumarizando as questões teóricas expostas e sua aplicação nesta pesquisa, cumpre destacar que, em relação aos efeitos da complexidade nas respostas avaliativas para o ambiente, é postulado que a agradabilidade seria significativamente maior para cenas com complexidade média do que para aquelas com complexidade baixa ou alta. A emoção seria maior para as cenas com complexidade alta, moderada para as cenas com complexidade média e menor para as cenas com complexidade baixa (NASAR, 1988).

Já em relação aos efeitos da coerência (obtida através da redução do contraste entre os elementos da cena) nas respostas avaliativas para o ambiente, é postulado que a agradabilidade seria maior para cenas com coerência alta (contraste baixo), moderada para cenas com coerência média (contraste médio) e menor para as cenas com coerência baixa (contraste alto). A emoção é baixa para as cenas com coerência alta (contraste baixo), moderada para as cenas com coerência média (contraste médio) e maior para as cenas com coerência baixa (contraste alto) (NASAR, 1988). 


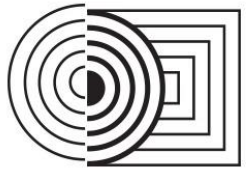

\section{$17^{\circ}$ ERGODESIGN \& USIHC 2019 \\ PUC-Rio, 11 a 13 de dezembro \\ Rio de Janeiro, RJ, Brasil}

$17^{\circ}$ Ergodesign - Congresso Internacional de Ergonomia e Usabilidade de Interfaces Humano Tecnológica: Produto, Informações Ambientes Construídos e Transporte

$17^{\circ}$ USIHC - Congresso Internacional de Ergonomia e Usabilidade de Interfaces Humano Computador

\section{CONSIDERAÇÕES TEÓRICO-METODOLÓGICAS}

Uma Sentença Estruturadora, instrumento básico da Teoria das Facetas (TF), procedimento metodológico fundado e desenvolvido por Louis Guttman, foi adotada para a estruturação da investigação empírica. Seu uso envolve a identificação dos diferentes conceitos que delineiam a pesquisa e consiste em estabelecer hipóteses de pesquisa, encontrar facetas do modelo teórico e definir os elementos que as constituem. Assim, cada faceta representa uma categoria conceitual, constituída por subcategorias de elementos a serem pesquisados.

De acordo com Bilsky (2003), a TF opera com três tipos básicos de facetas. O primeiro tipo se refere à população que irá avaliar as facetas (faceta de background); o segundo tipo ao conteúdo dessas variáveis (facetas de conteúdo); o terceiro tipo às possibilidades de respostas comuns a todas as facetas (faceta de racional).

De acordo com Costa Filho (2014), diversas pesquisas anteriormente desenvolvidas demonstram que, normalmente, existem três facetas básicas de avaliação de lugares e cada uma representa um componente do lugar a ser investigado: referente, foco e nível. A faceta do referente da experiência expõe os diferentes aspectos que as pessoas se baseiam para realizar suas avaliações. A faceta do foco modula o referente da experiência. A faceta do nível evoca a existência da escala ambiental, que influi na avaliação de lugares. As relações entre os diversos aspectos da experiência das pessoas com o ambiente estão na sentença estruturadora, que descreve os componentes do ambiente e a forma como eles são experienciados pelos usuários. A partir dessas definições, foi formulada a sentença estruturadora para a avaliação da agradabilidade percebida em salas de aula para o ensino superior, representada no Quadro 01, que reflete as relações entre os elementos internos das facetas do referente da experiência (o foco e o nível da experiência não variam), sendo precisamente essas relações que serão testadas na situação empírica através de imagens.

Quadro 1 - Sentença estruturadora para a avaliação da agradabilidade em sala de aula para o ensino superior

\begin{tabular}{|lc|}
\hline Em que medida a pessoa ( $\mathbf{x}$ ) avalia que as características ambientais de \\
(FACETA A) - REFERENTE & (FACETA B) - REFERENTE \\
COMPLEXIDADE & CONTRASTE \\
(A1) complexidade baixa & (B1) contraste baixo \\
(A1) complexidade média & (B1) contraste médio \\
(A1) complexidade alta & (B1) contraste alto \\
(RACIONAL) & \\
(1) nada & \\
(2) pouco & \\
(3) mais ou menos & \\
(4) muito & \\
(5) demais & estar e permanecer em uma sala de aula do ensino superior \\
\hline
\end{tabular}

Fonte: autores da pesquisa (2019)

Nessa sentença estruturadora para a avaliação da agradabilidade em sala de aula para o ensino superior, os elementos internos das variáveis complexidade e contraste podem ser organizados de forma semelhante a uma análise combinatória, produzindo nove diferentes conjuntos $(A 3 \times B 3=A B 9)$ ou diferentes situações a serem avaliadas.

Esse conjunto de nove cenas foi utilizado como elementos de estímulo em um questionário online. Cada uma dessas cenas está diretamente relacionada às variáveis desta pesquisa, listadas na sentença estruturadora para a avaliação da agradabilidade percebida em salas de aula para o ensino superior, todas selecionadas no "Google Imagem", levando em conta a complexidade e o contraste em três diferentes níveis (Quadro 2). 


\section{$17^{\circ}$ ERGODESIGN \& USIHC 2019}

PUC-Rio, 11 a 13 de dezembro

Rio de Janeiro, RJ, Brasil $17^{\circ}$ Ergodesign - Congresso Internacional de Ergonomia e Usabilidade de Interfaces Humano Tecnológica: Produto, Informações Ambientes Construídos e Transporte

$17^{\circ}$ USIHC - Congresso Internacional de Ergonomia e Usabilidade de Interfaces Humano Computador

Quadro 2 - Salas de aula para o ensino superior representando as relações de complexidade e de contraste

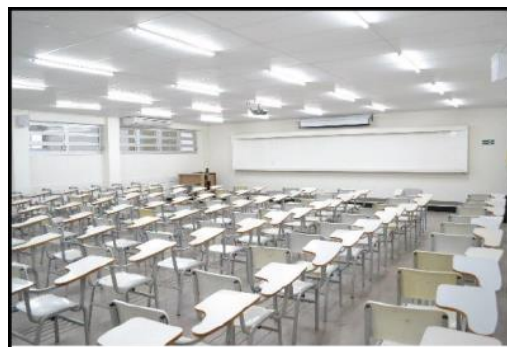

Sala de aula 01

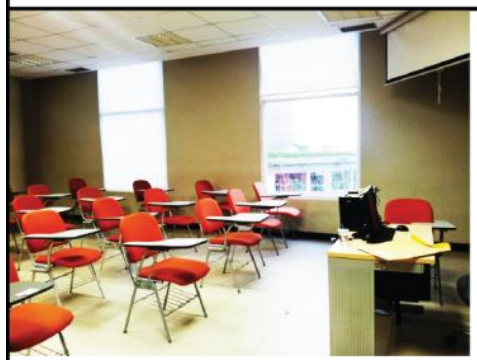

Sala de aula 03

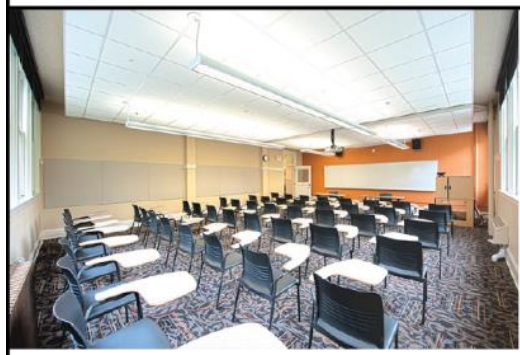

Sala de aula 05

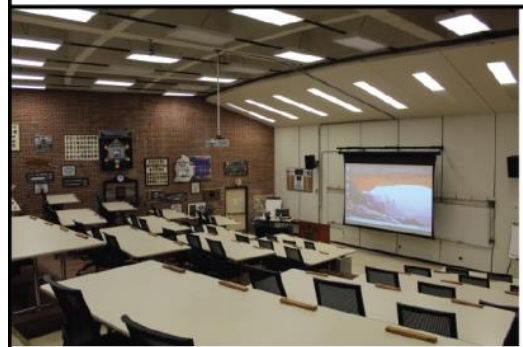

Sala de aula 07



Sala de aula 09



Sala de aula 02

A1B2

A1B1

Sala de aula 02

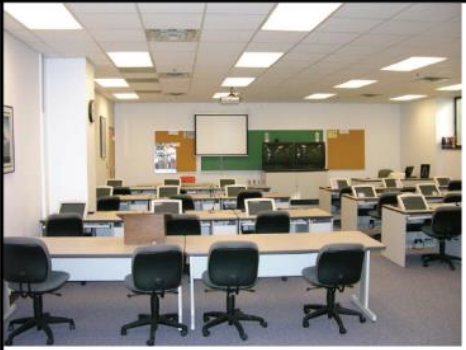

A1B3

Sala de aula 04

A2B1

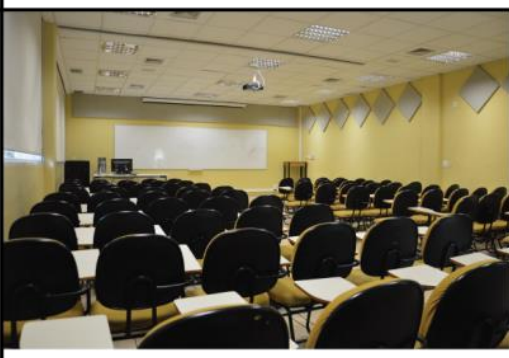

A2B2

Sala de aula 06

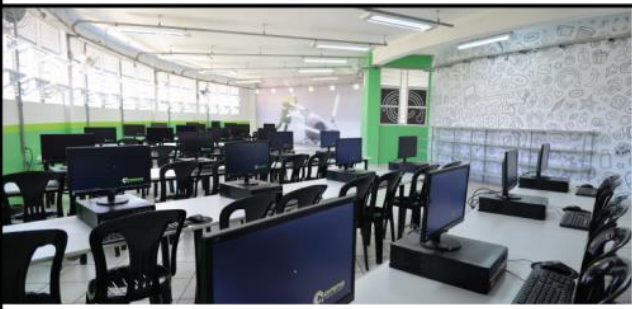

A3B1

Sala de aula 08

A3B2

\begin{tabular}{|l|l|}
\hline COMPLEXIDADE (A) & \multicolumn{1}{|c|}{ CONTRASTE (B) } \\
\hline $\begin{array}{l}\text { (A1) complexidade baixa } \\
\text { (A2) complexidade média }\end{array}$ & (B1) contraste baixo \\
(B2) contraste médio \\
(A3) complexidade alta & (B3) contraste alto \\
\hline
\end{tabular}

A3B3

Fonte: Google imagens 


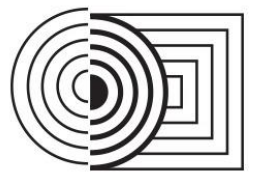

\section{$17^{\circ}$ ERGODESIGN \& USIHC 2019 \\ PUC-Rio, 11 a 13 de dezembro \\ Rio de Janeiro, RJ, Brasil}

$17^{\circ}$ Ergodesign - Congresso Internacional de Ergonomia e Usabilidade de Interfaces Humano Tecnológica: Produto, Informações Ambientes Construídos e Transporte

$17^{\circ}$ USIHC - Congresso Internacional de Ergonomia e Usabilidade

de Interfaces Humano Computador

A investigação empírica contou com um questionário online, criado por meio da ferramenta "Formulário Google", para coletar os dados. O questionário gerado foi baseado no Sistema de Classificações Múltiplas que, segundo Costa Filho (2014), consiste em solicitar aos participantes para classificar os mesmos elementos diversas vezes, com a finalidade de compreender suas ideias sobre o objeto de estudo.

O questionário foi divulgado através de redes sociais, e a escolha dessa ferramenta se deu pela praticidade e conveniência de ser um meio em que se conseguiria maior número de respondentes, além de permitir o uso de imagens.

Quanto às instruções de pesquisa, inicialmente foi informado aos respondentes que: (i) o estudo focava na avaliação visual de salas de aula do ensino superior; (ii) não havia resposta certa ou errada; (iii) garantia-se sigilo e anonimato.

Em seguida, após as informações introdutórias sobre o perfil do participante, era pedido que este indicasse em que medida cada cena de sala de aula para o ensino superior favorecia sua vontade de estar e permanecer naqueles ambientes.

Como universo de respostas, foram ofertadas cinco opções, que iam de "nada" (mínimo favorecimento) até "demais" (máximo favorecimento), passando pela opção "mais ou menos" (intermediário favorecimento). O número indicado entre parênteses, ao lado de cada opção dessa escala no Quadro 2, representa o valor a ser registrado na tabulação dos resultados em cada uma dessas possibilidades de respostas.

Ao final da pesquisa, contou-se com a participação de 20 respondentes com nível de escolaridade superior completo e idade entre 29 e 56 anos, sendo a maioria delas formada por eram mulheres (15), essas com idade entre 29 e 43 anos.

\section{CONSIDERAÇÕES EMPÍRICAS}

A partir da análise dos resultados - para os cinco diferentes níveis da escala proposta - como respostas avaliativas para a agradabilidade percebida nas nove cenas de salas de aula para o ensino superior, foi possível verificar o efeito da complexidade e da coerência na agradabilidade percebida nesse tipo de ambiente.

Em geral, os resultados obtidos omitem o efeito esperado da complexidade e da coerência nas respostas avaliativas para a agradabilidade percebida.

Considerando primeiramente os resultados para a complexidade, a agradabilidade é elevada nas salas de aula para o ensino superior com complexidade alta, sendo reduzida para aquelas com complexidade baixa.

Considerando, agora, os resultados para o contraste (coerência), a agradabilidade é elevada nas salas de aula para o ensino superior com contraste alto (coerência baixa), sendo reduzida para aquelas com contraste baixo (alta coerência).

Assim, os resultados omitem o efeito esperado da complexidade e da coerência para a agradabilidade percebida em salas de aula para o ensino superior. A cena de número 09 (Quadro 2), sala de aula para o ensino superior com complexidade alta e contraste alto (coerência baixa), foi percebida pelos respondentes como a mais agradável. Inversamente, a cena de número 06 (Quadro 2), sala de aula para o ensino superior com complexidade média e contraste alto (coerência baixa), foi percebida pelos participantes como a menos agradável. Pelo viés teórico, a agradabilidade é significantemente aumentada com a complexidade média, uma vez que a complexidade mínima é postulada como monótona e entediante, enquanto a complexidade alta é caótica e estressante. O resultado empírico obtido nesta pesquisa destoa dos postulados teóricos para a agradabilidade percebida em ambientes (Figura 01). 
$17^{\circ}$ ERGODESIGN \& USIHC 2019

PUC-Rio, 11 a 13 de dezembro

Rio de Janeiro, RJ, Brasil $17^{\circ}$ Ergodesign - Congresso Internacional de Ergonomia e Usabilidade de Interfaces Humano Tecnológica: Produto, Informações Ambientes Construídos e Transporte

$17^{\circ}$ USIHC - Congresso Internacional de Ergonomia e Usabilidade

de Interfaces Humano Computador

Figura 01 - Agradabilidade percebida nas cenas de salas de aula para o ensino superior

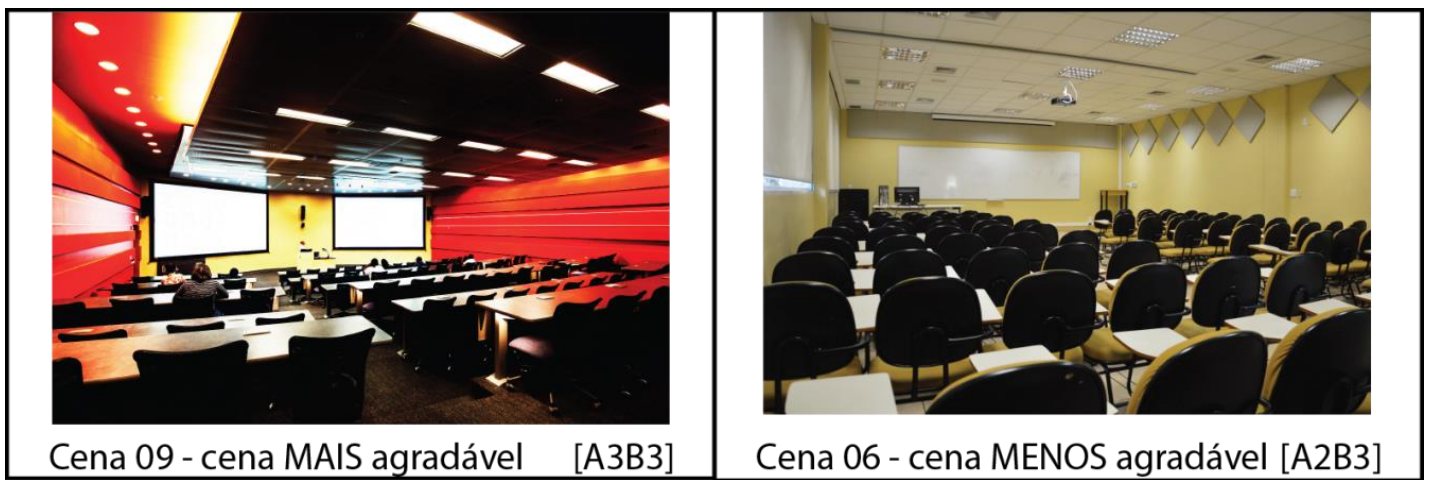

Fonte: Google imagens

A ferramenta "Formulários Google", fornece, ainda, a possibilidade de se verificar as respostas do questionário através de gráficos, por cena. Nas Figura 02 e 03 podemos verificar como foram distribuídas as respostas do questionário para estas cenas consideradas a mais agradável e a menos agradável, segundo esta investigação empírica.

Figura 02 - Gráfico da cena 09 considerada MAIS agradável

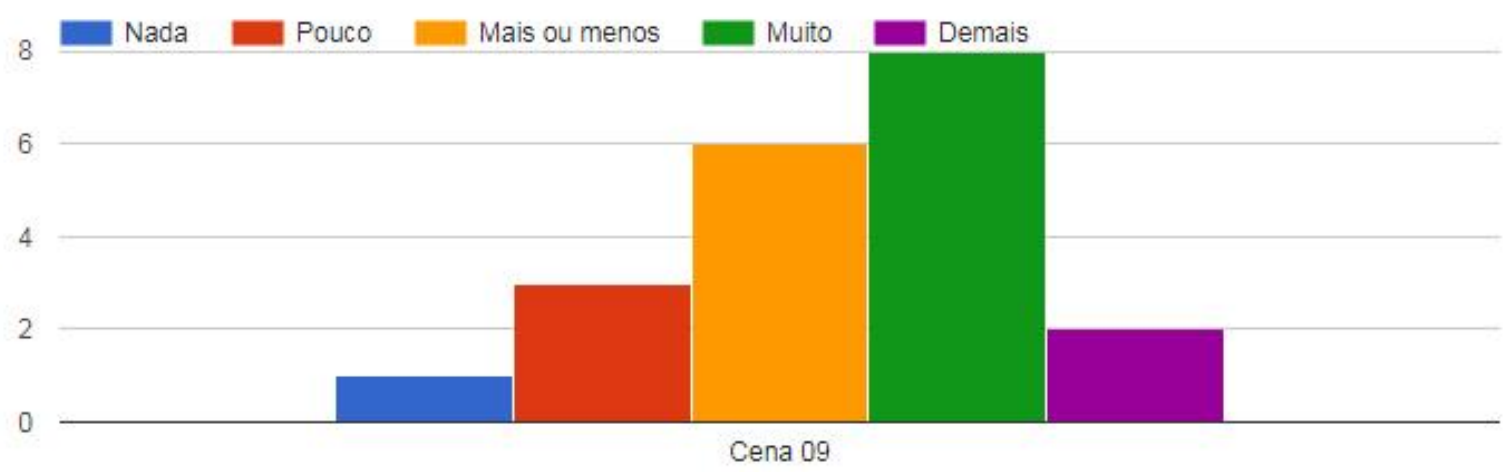

Fonte: Formulários Google

Figura 03 - Gráfico da cena 06 considerada MENOS agradável

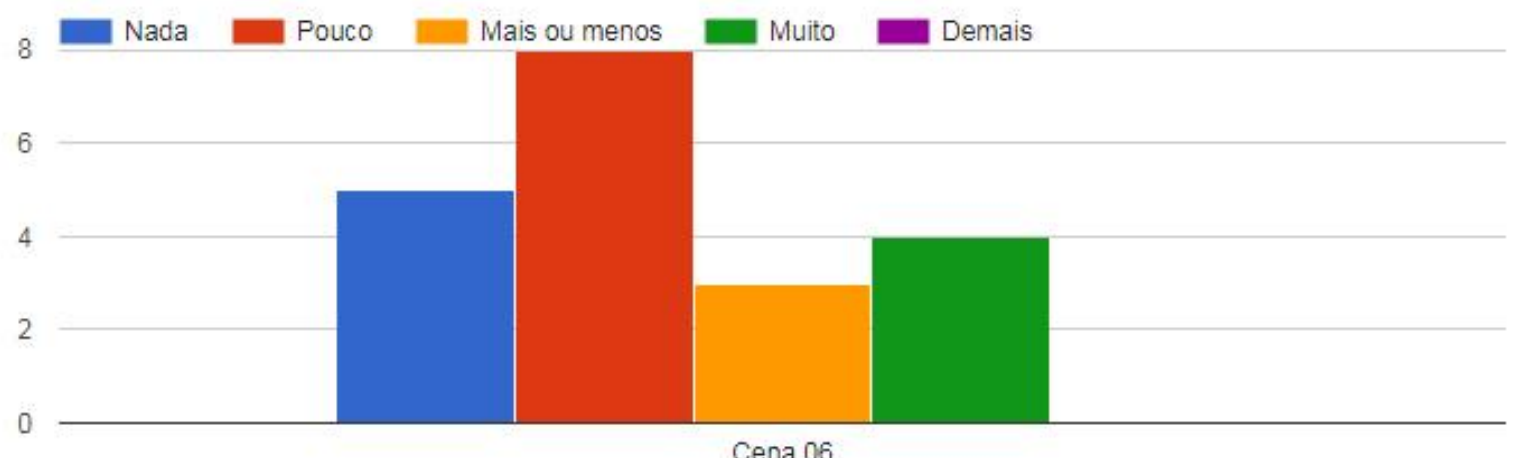

Fonte: Formulários Google 


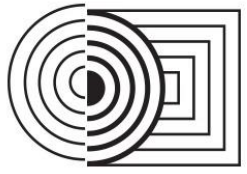
$17^{\circ}$ ERGODESIGN \& USIHC 2019

PUC-Rio, 11 a 13 de dezembro Rio de Janeiro, RJ, Brasil $17^{\circ}$ Ergodesign - Congresso Internacional de Ergonomia e Usabilidade de Interfaces Humano Tecnológica: Produto, Informações Ambientes Construídos e Transporte

$17^{\circ}$ USIHC - Congresso Internacional de Ergonomia e Usabilidade de Interfaces Humano Computador

\section{CONCLUSÃO}

A avaliação da agradabilidade percebida em salas de aula para o ensino superior tem importância e justifica-se por criar uma base objetiva para decisões projetuais que envolvam a qualidade visual percebida nesses espaços, aqui privilegiando a dimensão afetiva de agradabilidade.

Conforme demonstrado, foi verificado que os principais resultados empíricos desta pesquisa destoam dos postulados teóricos para a agradabilidade percebida em ambientes, que sugerem o nível de complexidade média, quando aqui a cena mais agradável foi a de complexidade alta e de contraste alto (coerência baixa) entre seus elementos ambientais.

É importante ressaltar que a amostra de indivíduos respondentes com o número de 20 pessoas pode ser considerada pequena e, talvez por isso, possa estar relacionada com a inconsistência. Destaca-se que a sala de aula para o ensino superior deve ser um local dinâmico, que requer metodologias ergonômicas de projetos que acompanhem essa dinamicidade, para poder refletir as necessidades afetivas de seus usuários, como a agradabilidade percebida do local.

\section{REFERÊNCIAS BIBLIOGRÁFICAS}

BERLYNE, D. E. Ends and meanings of experimental aesthetics. Canadian Journal of Psychology, 26, 1972.

BILKSY, W. A Teoria das Facetas: noções básicas. Estudos de Psicologia, v.8, n.3. p. 357365. 2003.

COSTA FILHO, L. L. O enfoque da teoria das facetas na avaliação de lugares. In: V ENEAC ENCONTRO NACIONAL DE ERGONOMIA DO AMBIENTE CONSTRUÍDO E VI SEMINÁRIO NACIONAL DE ACESSIBILIDADE INTEGRAL, 2014. Rio de Janeiro. Anais... Rio de Janeiro, PUC-Rio, LEUI/PUC - Rio. 2014.

FERNÁNDEZ-RAMÍREZ, B; REBOLLOSO, E; CANTÓN, P. The Nominal Group Technique and the environmental evaluation of university classrooms. Medio Ambiente y Comportamiento Humano, v. 8, n. 1-2, p. 49-70, 2007.

KAPLAN, S. Perception and landscape: Conceptions and misconceptions. In: NASAR, J. L. (Ed.). Environmental aesthetics: theory, research, and application. New York: Cambridge University Press, 1988.

MORAES, A; MONT'ALVÃO, C. Ergonomia: conceitos e aplicações. 4. ed. ampliada. Rio de Janeiro: 2AB, 2009.

NASAR, J. L. The evaluative image of places. In WALSH, W. B.; CRAIK, K. H; PRINCE, R. H. 2nd ed. (Eds.). Person-environment psychology: new directions and perspectives, pp 117168. New Jersey: Lawrence Erlbaum Associates, 2000.

The effect of sign complexity and coherence on the perceived quality of retail scenes. In NASAR, J. L. (Ed.). Environmental Aesthetics: theory, research, \& applications. New York: Cambridge University Press, 1988. p. 300-320.

RAPUANO GUIDALLI, C. R. Diretrizes para o projeto de salas de aula em universidades visando ao bem-estar do usuário [Dissertação de Mestrado] Programa de Pós-Graduação em Arquitetura, Florianópolis, SC, 2012.

RYKWERT, J. A sedução do lugar: a história e o futuro da cidade. São Paulo: Martins Fontes, 2004.

SANOFF, H. School building assessment methods. 2001. Disponível em: <http://www.edfacilities.org/pubs/sanoffassess.pdf>. Acesso em: 05 outubro 2018. 
SANOFF, Henry. Visual research methods in design. Nova lorque: Van Nostrand Reinhold, 1991.

VILLAROUCO, V. Tratando de ambientes ergonomicamente adequados: seriam ergoambientes? In MONT'ALVÃO, C; VILLAROUCO, V. (Orgs.). Um novo olhar sobre o projeto: a ergonomia do ambiente construído. Teresópolis: 2AB, 2011.

WARD, L.; RUSSEL, J. Cognitive set and the perception of place. Environment and Behaviour, v. 13, n. 5, 1981.

WOHWILL, J. Environmental aesthetics: The environment as a source of affect. In: ALTMANN, I.; WOHWILL, J. F. (Eds.), Human Behaviour and Environment, V. 1, 1976. p 37-86. 